\title{
New Horizons in the Evolutionary Science of the Human Family
}

\author{
Gregory Gorelik \\ Florida Atlantic University
}

\author{
Todd K. Shackelford \\ Oakland University
}

\author{
Catherine A. Salmon \\ University of Redlands
}

\begin{abstract}
Familial relationships cannot be properly understood outside of an evolutionary framework. Pseudoscientific and traditional modes of thought have steered us away from an accurate account of ourselves and our kin. Recent theoretical and empirical advances in the evolutionary sciences, such as the theories of inclusive fitness, parental investment, and parent-offspring conflict, have aided our understanding of familial conflict and cooperation. We suggest that a gene's eye perspective of human families can likewise illuminate much of human psychology and behavior by contrasting individual interests with genetic interests. Furthermore, theoretical and empirical work on genetic imprinting and extended phenotypic action-at-a-distance have unveiled the extent to which co-evolutionary arms races and manipulation lie at the heart of familial interactions and psychological disorders. We posit that human cultural trends and morals can ultimately be grounded on an evolutionary foundation: not only do human laws and institutions reflect group-level manifestations of gene-level cooperative adaptations, but also they may reflect gene-level manipulative adaptations. An awareness of evolutionary dynamics can advance human well-being and unveil the hidden mechanisms beneath all human and nonhuman relationships.
\end{abstract}

Keywords: family relationships, kin selection, inclusive fitness, extended phenotype, adaptation

For all the time we spend with and think about our kin, accurate information on the workings of the human family is not widely on offer. Amid the current of popular talk shows like Dr. Phil or Dr. Laura, as well as a host of books and self-help media, there is little honest, evidenced-based information to help us understand our familial relationships. There is, however, much proselytizing by religious figures and media ideologues on the breakdown of the modern family. Self-titled gurus and even some medically trained professionals are disseminating advice that is false and sometimes dangerous. Although this article is not meant to offer therapeutic guidance for mending the wounds of familial conflict, it does provide an evidenced-based account of the dynamics behind family relationships. By understanding our evolutionary past and the selection pressures that bombarded our ancestors, we can begin to form a stable foundation that will guide our academic, practical, and ethical decisions in dealing with the trials and tribulations of kinship.

\section{The Unveiling of Familial Nature}

Just as Rousseau's (1755) depiction of a wholly peaceful human nature was overturned by Darwin's (1859) theory of natural se-

Gregory Gorelik, Department of Psychology, Florida Atlantic University; Todd K. Shackelford, Department of Psychology, Oakland University; and Catherine A. Salmon, Department of Psychology, University of Redlands.

Correspondence concerning this article should be addressed to Gregory Gorelik, Florida Atlantic University, Department of Psychology, 777 Glades Road, Boca Raton, FL 33431. E-mail: ggorelik@ fau.edu lection, current explorations in evolutionary biology and psychology cast doubt on the idea that a family is a coherent unit of cooperative individuals, with familial conflict only occurring when otherwise functional family relationships break down (Kurland \& Gaulin, 2005; Salmon, 2005). With the modern evolutionary synthesis in biology, as well as the subsequent developments of kin selection and selfish gene theory, science has been unveiling the extent to which familial conflict is the product of selection.

Hamilton's (1964) theory of inclusive fitness provided a theoretical framework for predicting instances of familial discord as well as cooperation. According to this theory, the more genetically distant a relative is from another relative, the more likely it is that conflict between them will occur. In fact, when there is any genetic heterogeneity between interacting individuals, some form of conflict is inevitable, regardless of whether they are related. Distant relatives do not share as many genes for helping one another as do close relatives. For example, because monozygotic twins share $100 \%$ of their genes, they are likely to value each other as much as they value themselves. Meanwhile, parent-child and full sibling relationships, which are based on a genetic similarity of only $50 \%$, are expected to exhibit conflict as well as cooperation. The same reasoning can be extended to more distant networks of interrelatedness, with individuals investing more in their grandchildren, for instance, than in their third cousins (e.g., Chrastil, Getz, Euler, \& Starks, 2006). Of course, the proportion of shared genes is not the only factor determining how much investment is provisioned to family members. Ecological circumstances such as the availability of food, as well as the health, age, and reproductive prospects of family members are also considered when deciding whether to benefit one's kin (see Coall \& Chisholm, 2010, for an example of life history tradeoffs in parental care). 
In general, organisms tend to behave indifferently toward one another. Outright cooperation and conflict are costly and are only engaged in if the reproductive benefits outweigh the expenditures in time and energy. In many species, even relatives tend to be ignorant of each other's existence. In some species, however, genes coding for altruism toward kin may spread within a gene pool by favoring relatives who are likely to carry copies of the same genes. Such is the case with humans. Our nepotistic tendencies are results of millions of years of selection for genes that selfishly benefited copies of themselves. While our proximate thoughts and feelings enable us to feel love and affection for our family members, the ultimate evolutionary reason behind that love and affection is genetic self interest-although of course this in no way invalidates the power and importance of such feelings. Furthermore, when there is genetic incongruity between kin that spend a great deal of evolutionary time interacting with one another (as parents and children do within our own species, characterized by a prolonged period of dependence on parental care; see Bjorklund, Periss, \& Causey, 2009), co-evolutionary arms races are expected to occur (Haig, 2010; Hudson \& Trillmich, 2008). Far from being confined to predator-prey interactions, co-evolutionary arms races characterize many of our most cherished familial relationships. The human family is rife with evolved weaponry for mutual exploitation

\section{All's Fair in Love and War}

Following in Hamilton's footsteps, subsequent investigations in the biological sciences indicated that familial conflict runs deeper than expected. In a series of groundbreaking papers, Trivers proposed a number of adaptations that organisms possess for manipulating and extracting resources from their kin. His theory of parental investment (1972), for instance, examined the diverging reproductive interests of males and females. According to parental investment theory, the sex with the greater minimum investment necessary to produce and rear offspring to reproductive age will be more discriminating when it comes to choosing sexual partners. In most mammals, females incur greater minimum reproductive costs than males as a result of pregnancy and lactation. By choosing the "wrong" male, females risk squandering valuable reproductive resources by investing in genetically inferior offspring or risk copulating with a male who is unlikely to provide resources to help her successfully raise an offspring to adulthood. As a result, females are expected to have evolved psychological adaptations for discriminating genetically superior and resource-rich suitors from genetically inferior and resource-deficient suitors. In contrast, males are likely to have evolved adaptations for attempting to copulate with multiple females (since males pay less in reproductive costs when copulating with genetically inferior females than vice versa) and for minimizing investment in offspring that they did not sire. This war of the sexes has been raging as a coevolutionary arms race between ancestral males and ancestral females. Although sexual reproduction can be a cooperative venture, it is likely that human romantic relationships are rife with deceptive and manipulative strategies that were selected into each sex because they proved successful at manipulating members of the opposite sex.

In humans, women may manipulate men to extract resources (by promising them sexual favors, e.g.), prevent them from investing in rival women and their offspring through psychological manipulation and commitment jealousy, or cuckold them by surreptitiously producing offspring sired by genetically superior men (see Buss, 2003, for review). Men, on the other hand, are more likely to deceive women into thinking that they are of higher genetic quality or are better able and more likely to invest in long-term romantic commitment and child rearing than they actually are. Along with body language and verbal behaviors, members of both sexes may use clothing and accessories to manipulate members of the opposite sex as part of their reproductive strategy. Some manipulative reproductive strategies are sex-differentiated (see Buss, 2003, for review): Women are more likely to engage in appearance enhancing behaviors to communicate youth and fertility, and men are more likely to exaggerate their wealth, generosity, and social standing to communicate their willingness and ability to invest in a woman and her offspring. Men also appear to have adaptations for manipulating the sexual behavior of their partners in order to minimize the risk of investing in offspring sired by a rival (e.g., Goetz, Shackelford, Romero, Kaighobadi, \& Miner, 2008). These male adaptations include abusive and intimidating tactics as well as generous and affectionate behaviors aimed at preventing female infidelity (e.g., Miner \& Shackelford, 2010). Male and female sexual strategies, however, do not all fit the same pattern and may vary across an individual's life span as a result of contextual and life history circumstances (Neberich, Penke, Lehnart, \& Asendorpf, 2010), although genetic differences can account for some of the influence of personality characteristics on sexual strategies (see Kaighobadi et al., 2009, for the effect of male personality traits on the risk of partner-directed violence). Sexual jealousy as an evolved response to ancestral selection pressures of paternity uncertainty and the risk of partner abandonment may thus shed light on such divergent behaviors as romantic affection and spousal abuse.

On average, men are more interested in sexual variety than are women (Symons, 1979). Some men, however, may eschew a polygynous strategy in favor of a long-term commitment to a single woman, provided that such a strategy was reproductively successful for some male ancestors. The evolution in both sexes of long-term pair bonding mechanisms may have brought about selection for the intensely felt and even overpowering emotional reactions that characterize romantic love (see Buss, 1987, 2003). Such a seemingly irrational commitment to a member of the opposite sex may have been adaptive for our ancestors in motivating them to remain together long enough to raise an altricial child.

Future investigations into male-female interactions are needed to further map the structure and function of the adaptations employed by each sex against the opposite sex in the mating arena. The application of sexual selection theory to human mating strategies may likewise illuminate our understanding of human culture as a tool that is used to attract mates by communicating genetic worth or resourcefulness (see, e.g., Miller, 2000). Evolutionary approaches to human psychology and behavior can thus provide valuable insights into the origins and functions of our most sublime passions and affections.

\section{Parents and Children}

The conception of the parent-offspring relationship as the paragon of familial harmony is likewise being challenged by current 
investigations into parent-offspring conflict. The bond between a mother and her child is often regarded as the most pure and sacred of all family relationships. This sentiment is expressed in the iconic Christian image of Mary cradling her infant, a depiction of unbridled love and nurturance. Such idyllic cultural imagery, however, belies a more nuanced biological reality. Although the mother-child relationship is largely based on the evolutionary necessity for care and protection of altricial infants and children (e.g., Bjorklund et al., 2009), and although there are countless examples of parents sacrificing their own lives on behalf of their children, Trivers's (1974) theory of parent-offspring conflict implies an arms race between the reproductive interests of parents and offspring that may even lead to instances of child abuse and filicide. The evolutionary reason for this conflict boils down to sibling rivalry. Disregarding factors such as offspring age and health, a diploid mother's genetic interests are usually best served by apportioning her resources equally among all her offspring, because that mother shares the same proportion of her genes with each of them $(50 \%)$. Each offspring, however, values its own genes over the genes of its mother and siblings, and although relatives are more likely to cooperate than nonrelatives, the genetic interests of the offspring are sometimes best served by extracting more resources from its mother than the mother is willing to allocate. This resource extraction comes at the cost of the reproductive success of the offspring's mother and its current or future siblings, leading to the evolution of adaptations for manipulation on the part of both parents and offspring. In certain contexts, therefore, the genetic interests of parents and offspring are at cross purposes (Salmon, 2005). Even though humans are one of a few mammalian species in which fathers also provide some childcare, mothers are the primary caregivers in almost every society. As a result of these selection pressures, parent-offspring conflict is mostly fought between mothers and offspring (but see Patten \& Haig, 2008, for cases in which paternal and maternal genes compete within a single organism via genetic imprinting).

The tug-of-war between a mother and her offspring is evident at conception. Although the uterus is usually a supportive environment for a developing fetus, a fetus's adaptations for extracting nutrients from its mother may trigger the mother's physiological adaptations for limiting resource allocation to the fetus. In such instances, a fetus is parasitic on the mother and may even bring about a miscarriage. Miscarriages also occur when maternal adaptations register that the fetus is defective and unlikely to survive to reproductive age. For an expectant mother, a miscarriage can be an earth-shattering experience (Lee \& Slade, 1996). From an evolutionary perspective, it may reflect an evolved response on the part of the mother's body that may ultimately save her life. This may have been a last line of defense for an ancestral mother whose Pleistocene environment lacked the amenities of modern medicine.

If the infant survives gestation, its struggle with its mother over nutrients and maternal affection takes on wider behavioral dimensions. Infant crying, for instance, may signal an infant's genuine need for protection or sustenance, or be used as an honest indicator of infant quality, but it also can be manipulatively employed by the infant to prevent mothers from copulating and giving birth to sibling competitors (e.g., Lummaa, Vuorisalo, Barr, Lehtonen, 1997). For the same reason, a child may resist weaning in order to limit resource diversion to its current or future siblings. As children mature, sibling rivalry and parent-offspring conflict may be expressed in the contexts of playground privileges, priorities to the largest portion of dessert, or demands for the best Christmas present. Once puberty arrives, adolescents and parents may engage in conflict over adolescent mating decisions (Apostolou, 2009). For example, parental genetic interests may be better served by their daughters engaging in long-term mating, but daughters may reproductively benefit their own genes by engaging in short-term mating and relying on parents to help them raise resultant offspring. Thus, parent-offspring conflict may be in motion whenever parents prevent adolescents from associating with members of the opposite sex of whom they disapprove. Likewise, adolescents can adaptively rebel against their parents' wishes by staying out late or keeping friends whose influence upon their sexual behavior may conflict with parental interests. The hidden biological dynamics of parent-offspring conflict over mating decisions may yet explain the timeless appeal of Shakespeare's Romeo and Juliet.

All evolutionary relationships fall along a continuum of conflict at one end and cooperation at the other. Relationships between different genes and organisms reflect the selection pressures that gave rise to them. Some of these relationships are characterized by mutual benefit, whereas others reflect generations of conflict and arms races. Evolutionary relationships characterized by genetic kinship, however, fall somewhere in between the two extremes. Although an organism may reap genetic benefits by investing in kin with whom genes for benefitting kin are shared, exploitation of one's kin is also expected when there is genetic distance between the interacting kin. Furthermore, adaptations for dealing with kin may be extended or coopted when genetically unrelated organisms benefit from or parasitize one another via the redirection of adaptations that are normally aimed at benefitting or manipulating relatives (Archer, 1997; Qirko, 2004; Salmon, 1998).

\section{The Long Reach of Our Genes}

In the following section, we discuss how genetic interests may influence human psychology and behavior. In particular, we discuss several possibilities for how humans may have evolved to psychologically manipulate family members. We also discuss how genetic mechanisms may be responsible for much of our technological and cultural functioning. Many of our arguments are speculative, but serve to showcase the kinds of evolutionary arguments that should not be neglected by psychologists. It is no longer feasible for social scientists to ignore the biological roots of humanity. The threat of controversy is not enough to forestall the scientific progress that can be achieved when we apply evolutionary biology to human psychology and behavior.

We are fractionated from within and without. No longer can we consider ourselves to be working solely for the evolutionary benefit of our individual selves. Hamilton's (1964) theory of inclusive fitness and Dawkins's (1976) popularization of selfish genes brought about the realization that genetic interests do not always coincide with the interests of the individual organism. It may be helpful to view the family as consisting of networks of genes that seek to propagate themselves by coding for programs that either benefit and form alliances with one another, or exploit one another, rather than as consisting of individual family members. The evolutionary success of these programs is ultimately judged by whether the genes coding for them are naturally selected over rival alleles within the gene pool. To the extent that a mutation contrib- 
utes to the cooperative or manipulative effort of programs that function within the family environment, it will propagate itself within the gene pool and contribute to the co-evolutionary processes that characterize kinship relations. Indeed, this perspective helps to illuminate the evolution of all biological systems.

The relationship between a gene and its phenotypic effects is nonlinear. The developmental process is characterized by a complex bidirectionality whereby a gene's expression depends on the other genes within its environment as well as the ecological cues that activate it (see, for review, Bjorklund \& Pellegrini, 2002). This leaves much room for the influence of competing factors on a gene's phenotypic expression, whether anatomical, physiological, psychological, or behavioral. To the extent that we spend a substantial portion of our lives surrounded by kin, beginning with conception, there is much opportunity for our close kin to manipulate the developmental outcomes of our phenotypic programs. Our genes, however, are not idle pacifists and do not absorb without recourse the manipulation of their developmental expression; our evolution has likely included selection for phenotypic defenses against the manipulative strategies possessed by our kin. This may have resulted in an arms race whereby our kin's genes are selected for how well they can direct our ontogenetic course for their own benefit, and our own genes are selected based on how well they code for phenotypic expressions that resist being manipulated during our development (which may help to explain the paradoxical finding that parental rearing practices have little direct effect on subsequent offspring outcomes, although it remains to be seen whether parents may influence their offspring's development via more implicitly acting adaptations to parent-offspring conflict; see Harris, 2009). This genetic battle can even occur between the maternal and paternal genes within an individual organism, whereby one parent's genes can code for physiological processes or behaviors that inflict a cost upon the genes of the other parent (Haig, 2004). In this sense, it is more accurate, biologically speaking, to view families as self-promoting networks of genetic interests rather than as self-promoting individual organisms.

We likewise possess the same adaptations for manipulating, as well as benefitting our own offspring, provided that we ourselves reproduce. Thus when we are in the role of offspring, certain genetic programs and psychological mechanisms for extracting resources from our caregivers are turned on, while other, contextually irrelevant programs and mechanisms are turned off. Once we become parents, latent genetic programs and psychological mechanisms for manipulating as well as benefitting our own offspring come online. In a spectacle of evolutionary irony, the evolved mechanisms used by our parents to manipulate us in our youth are used by us as tools to manipulate our own offspring. Such is the evolutionarily derived cycle that characterizes our developmental journey through life.

According to Belsky (2000), parental investment strategies can influence offspring attachment styles, pubertal timing, and sexual behavior. Girls that form insecure attachments to their fathers, for instance, are likely to experience earlier onset of menarche and pregnancy than are girls who receive reliable paternal resources and care. This corroborates the results of Maestripieri, Hoffman, Anderson, Carter, and Higley's (2009) research which demonstrates how maternal styles can influence the subsequent developmental trajectories of rhesus macaques. These findings can be interpreted by positing that parents have evolved manipulative strategies to influence the physiological, psychological, and behavioral development of their children. On the opposite side of the arms race, children may have evolved defensive strategies to minimize the influence of parental strategies on their development. It may be that children's developmental outcomes are not only the results of parental manipulation, but also reflect evolved solutions to the life history trade-offs that they experience throughout their development. Both scenarios should be investigated empirically.

Whenever one organism (or gene) manipulates the behavior of a different organism (or gene) for its own reproductive benefit, it is using the manipulated organism (or gene) as an extended phenotype of itself (Dawkins, 1982). This action-at-a-distance gives manipulator programs long-reaching power in manipulating their environments. The manipulated organisms can be viewed as phenotypic manifestations of manipulator organisms. This approach can help us to understand intersexual and intrasexual relationships, as well as parent-offspring relationships. Co-evolutionary relationships between members of the same species can result in selection for mutually manipulative strategies that are either evolutionarily stable, in which each strategy is at its adaptive peak and can do no better, or evolutionarily unstable, in which a runaway arms race ensues and ever-more manipulative, countermanipulative, and defensive strategies evolve. Both stable and unstable arms races may exist in our own species, in which individuals have evolved strategies to use other individuals as extended phenotypic tools for their own benefit (see, for review, Dawkins, 1982).

Humans may manipulate each other in circumstances in which deception and manipulation helped our ancestors best their reproductive rivals by controlling the rivals' behaviors. Studies of language use within politics, economics, and everyday situations can aid our understanding of how our adaptations for deceiving our rivals are verbally and culturally expressed, and how language and culture, in turn, can influence the evolutionary and developmental trajectories of our manipulative extended phenotypic adaptations (Earley, 2010; Melis \& Semmann, 2010). Likewise, the proximate manifestations of parent-offspring conflict can be examined from the perspective of the extended phenotype by measuring individuals' behaviors as a function of their kin's manipulative strategies. For example, young mothers with high future reproductive prospects may limit their investment in reproductively unpromising offspring by manipulating their offspring's psychological state or behavior. In a study by Brown et al. (2009), university students' risk of suicide was predicted by their mother's age, how burdensome they felt they were to their families, and their degree of romantic satisfaction. Parents may possess adaptations for relieving their burden of a reproductively unpromising child by using that child as an extended phenotypic tool of their own reproductive interests. Thus, parental adaptations for manipulating offspring psychology and behavior may have been selected if these adaptations successfully brought about the death of a reproductively unpromising and resource-draining offspring. Although speculative, such controversial hypotheses must not be neglected if we are to understand the evolutionary dynamics behind family relationships. Parental manipulation of offspring depression and suicidal ideation may have had lower social costs than direct filicide and thus, along with filicide, may have been selected. Suicide may even have been evolutionarily adaptive to the offspring's genetic interests provided that the genes coding for kin-directed altruism are benefitted thereby. Likewise, parents may use their children as 
extended phenotypic tools to acquire sexual partners, similar to the way in which individuals may use their pets to display their resources or empathetic qualities to potential mates (Daly \& Morton, 2009). In the future, researchers might investigate the specific behavioral, neural, and hormonal pathways by which individuals influence the emotions, cognitions, and behaviors of other individuals. Of course, such a scientific investigation in no way excuses psychological abuse, filicide, or the manipulation of individuals; understanding the evolved strategies that humans employ against other humans does not morally sanction them.

The cultural correlates of parent-offspring conflict can be analyzed by examining the extent to which parents, offspring, and siblings use tools and technologies to influence each other's behavior. The telephone and Internet may be useful tools for manipulating our families, friends, and neighbors. Parents may retain some extended phenotypic power over their children (regardless of whether their children are in the same household) if they continue to influence their children's behavior. For example, cellular phones and computers may provide parents with effective means of manipulating their physically distant children's reproductive behaviors by sending their offspring dating advice through email or text messages. Parents and grandparents are in more frequent contact with offspring in whom they invest the most (Salmon, 1999). Likewise, children may acquire a larger extended phenotypic reach over their parents if they are technologically savvier than their parents and can use technology to extract resources from them. The rapid increase in technological advancement that exemplifies our species may have produced novel selection pressures for unpredictable and innumerable arms races between related and unrelated individuals. With the aid of modern technology, our manipulative and defensive psychological mechanisms may have acquired unprecedented phenotypic powers, as later discussed.

\section{Therapeutic Implications of the Extended Phenotype}

In applying the extended phenotype model to therapeutic settings, we can better anticipate and perhaps avoid some of the pitfalls of psychologically treating individuals in isolation from their families and social networks. Psychological conditions such as depression and bipolar disorder may be indicative of genetic conflicts between patients and their kin, or internal conflicts between a patient's maternal and paternal genes. If individuals manipulate each other's psychological states and behaviors with evolved manipulative tactics, it is not sufficient to focus therapeutic treatments on individual patients - clinicians must be attentive to signs of psychological manipulation of patients by their families, friends, social structures and institutions, or by some of their own selfish genetic elements. Psychological symptoms such as paranoia may result from hyperactive adaptations that normally protect individuals from being manipulated by other individuals in their environments. Although the government may not be spying on a schizophrenic patient's every move, his or her paranoia may hint at a deeper conflict between the interests of state institutions and the patient's own reproductive interests, whether real or imagined. Likewise, adaptations that elicit fear and anxiety may misfire or be misapplied to novel contexts that were not present in our ancestral environments. Therefore, therapists may better aid their patients by applying evolutionary models to interpersonal and intrapersonal conflicts. Hearing voices or feeling conflicting emo- tions and cognitions may result from genetic imprinting of parental genes. Paternal genes may code for psychological systems that conflict with an individual's maternally coded psychological systems, and vice versa. The symptomatic results of this mismatch of psychological processes could include shame, guilt, or suicidal behavior. Patients may feel torn from within and therapists may see no hope for recovery. Although medications can greatly reduce some of the symptoms of psychosis, and cognitive and behavioral treatments can give patients tools for managing their intrusive thoughts and behaviors, clinicians might devise novel methods for dealing with the reverberations of this internal genetic conflict. If possible, medications for selectively suppressing the action of genes implicated in genetic imprinting may do well in conjunction with appropriate therapeutic techniques for lessening the burdens of patients. Evolutionarily informed pharmaceutical and genetic research is essential in devising such treatments for psychological and physiological disorders. Likewise, psychiatrists and psychologists might investigate the social and familial frameworks within which their patients operate. Interpersonal and family therapy, informed by an evolutionary perspective, can provide important insights for guiding future research into psychological treatments. More specifically, therapists may view the distressing symptoms of patients as the effects of manipulative tactics by other individuals In so doing, therapists can focus their treatments on lessening the burdens of such manipulative tactics instead of treating symptoms as breakdowns in the normal functioning of individuals.

Many of our adaptations for manipulating and deceiving others may have been selected to target family members (Cronk, 1995). The reason for this is that most of our ancestors' social interactions were limited to repeated encounters between kin. Thus, there may have been an implicit evolutionary rationale behind the psychoanalytic focus on maternal relationships within the therapeutic setting. Freud's folly, however, was in positing familial dynamics for which there was, and still is, little empirical support. On the other hand, The dynamics behind parent-offspring conflict have been documented in a number of widely diverse species, including humans. Post-partum depression, for example, may represent an evolved response on the part of a young mother to a resourcedraining infant (e.g., Hagen, 2002). By recognizing this evolutionary dynamic, therapists can devise effective treatments to inform their patients, improve their condition, and forestall the destructive effects that such evolutionary dynamics may have on patients and their significant others.

In conclusion, future investigations into familial friction and therapeutic treatments may benefit from an examination of interpersonal and intrapersonal conflict from the perspective of extended phenotypic manipulation. Such an evolutionarily grounded investigation may improve on earlier psychoanalytic discussions of familial conflict as expressed through unconscious processes. The examination of unconscious family dynamics from an evolutionary perspective may prove useful in isolating and examining the manipulative behaviors that family members employ against each other and against themselves as resulting from genetic conflicts of interest.

\section{Evolutionary Ethics of the Family}

In the final section of this article, we focus on the roles that arms races and mutual manipulation may play in human ethics and 
morality. This will not be a discussion of what is moral or ethical. We do not offer prescriptions for proper moral conduct, as this is beyond the scope of this article. In any case, the foregoing treatment of human adaptations to the family environment has shown how difficult it is to decipher moral rectitude and responsibility in a species that is rife with manipulative and deceptive tactics. Can genes or gene networks be held accountable for the actions of their phenotypic effects? Who (or what) has moral responsibility if individual actions are coded for by gene networks that transcend individual bodies? We believe that moral responsibility should not be sought on the genetic level. Whatever the genetic (or cultural) correlates of behavior are, judicial systems of deterrence and punishment are probably right to focus on the individual when assigning personal responsibility. While we should not excuse rape and murder by invoking biological motivations ("blame the genes!"), neither should we ignore the biological correlates of some of our most unsavory behaviors (for an excellent discussion of biology and moral responsibility, see Pinker, 2002).

Rather than devising methods for assigning genetic culpability, we discuss human morality from the perspective of evolved psychological mechanisms that seek to maximize the replication of the genes coding for their development. We also examine the social and cultural correlates of evolved moral sentiments whose ancestral domains were limited to familial and tribal interactions. Ours is a tentative approach and may be more useful for the questions posed than for the answers provided. It is incumbent upon investigators in the biological, psychological, and social sciences to empirically flesh out these issues.

For any social species, the benefits of interacting with other members of their species must exceed the costs of going solo. There are a number of evolutionary explanations for why organisms engage in cooperative relationships (see Trivers, 1985, for a review). The first is genetic relatedness and the mutual possession of genes "for" helping kin. Eusocial insects are notorious cooperators for this very reason and even put our own "family values" to shame. A second explanation for cooperation between organisms is based on the mutual exchange of favors, or reciprocal altruism (Trivers, 1971). For reciprocal altruism to evolve, organisms must interact repeatedly with one another and such interactions must persist for many generations. In these circumstances, the genetic interests of the interactants may be promoted through mutual cooperation. Provided that organisms gain a net reproductive advantage over their entire cooperative period by cooperating with other reciprocators, immediate returns of favors are not necessary for the selection of general cooperative tendencies. What is necessary, however, is the ability to distinguish cooperators from defectors, as defectors or cheaters may benefit by accepting favors without returning them. To guard against this threat, cooperators evolve "cheater-detection" mechanisms to avoid and punish cheaters (see Cosmides \& Tooby, 2005). This sets up an arms race in which cooperative strategies are pitted against deceptive strategies across evolutionary time. As cooperators become better at detecting cheaters, cheaters become better at deceiving and extracting resources from cooperators.

For humans, both kin favoritism and reciprocal altruism probably play a role in accounting for our sociality with respect to relatives as well as nonrelatives [for a different explanation of human generosity and altruism, see Miller's (2000) account of sexual selection in humans]. Cooperation between kin also may involve reciprocity, and cooperation between nonkin may involve the redirection of adaptations for benefiting kin (e.g., Qirko, 2004). For most of human evolutionary history, our ancestors lived in small tribal societies based mostly on kinship ties. If two individuals from the same society were unrelated, chances were high that both were related to a third individual. It is therefore likely that our moral and empathetic sentiments had their origins in adaptive acts of kindness directed toward individuals with whom genes "for" that kindness were shared. Likewise, the evolution of reciprocal altruism was enabled by the relatively small tribal societies within which individuals were forced into repeated interactions with their fellow tribesmen (rudimentary forms of such cooperative structures can be witnessed in some of our great ape cousins-see Watts, 1994; Watts \& Mitani, 2001). With the increasing population density of early hominids, selection pressures led to the evolution of complex social dynamics. Our ancestors' cooperative and manipulative tendencies gained unprecedented reach as a result of these selection pressures, likely contributing to an increase in brain size and the evolution of language. With an increase in brain size came a prolonged developmental period and the need for parental and alloparental care. Children became increasingly dependent on their caregivers to acquire the knowledge needed to cooperate with and manipulate other individuals in their densely populated environments. Because humans are a cultural species (in that our cognitive abilities are adapted to and express themselves within the contexts of rapidly changing informational and societal trends-i.e., language, technology, fashion, etc.), our evolved cooperative predispositions are dependent on culturally acquired values and mores for their proper development. In this way, the development of human morality entails adaptive attunement to certain familial and societal rules of conduct. Children's evolved learning mechanisms are specifically tuned to parental moral instruction early on in their development. This moral instruction was adaptive for children and parents alike in that children could learn the effective means by which to negotiate their social surroundings to mate and successfully replicate their parents' genes (see Bjorklund \& Pellegrini, 2002, and Bjorklund et al., 2009, for reviews of empirical and theoretical work discussed in this paragraph). When reflecting upon the dynamics of parent-offspring conflict, however, mutual benefit and cooperation is not all there is to moral instruction. Some familial rules of conduct may ultimately reflect extended phenotypic means by which individuals selfishly manipulate the behavior of their kin.

Extending biological and psychological findings to wider cultural phenomena is a risky endeavor. Human culture may function under rules and mechanisms that are unique to its domain. Nevertheless, human culture is a product of biological evolution and possesses an indelible stamp of its "lowly origin" (see Tooby \& Cosmides, 1992). As such, we next examine the cultural expressions of our evolved moral sentiments to better understand how familial arms races and conflicts play themselves out on our cultural stage. The tribal culture of our ancestors was different in many ways from our technologically interconnected global system. With advancements in transportation and communication technologies, the rate and extent of cultural change has been magnified to unprecedented levels. Taking into account this minefield of geneculture co-evolution, we limit our discussion and hypotheses to only a few societal trends. In doing so, we hope that researchers in 
diverse fields may apply some of these ideas to past and present societies across the globe.

Culture entails the group-level expression of gene-level adaptations for transferring non-genetic information within and across generations (see Tooby \& Cosmides, 1992). Notwithstanding arguments for group-level selection, adaptation entails the selective retention of some alleles over others within a gene pool (Williams, 1966). A primary vehicle of genetic expression is the individual organism, within which genes code for proteins in conjunction with other genes. On average, genes within an organism have been selected to cooperate with one another in building adaptations that are effective at propagating copies of those genes. Sometimes, however, genes can be selected at the expense of the other genes with which they share an organism, as in inclusive fitness or genetic imprinting, discussed earlier in the article. In humans, gene-level adaptations coding for individual-level psychological processes can be expressed as group-level cultural trends. In turn, group-level cultural trends may influence gene-level adaptations. Genes are still selected for how well they can replicate copies of themselves but some of those selection pressures result from the incidental group-level effects of genetic programs. Therefore, there is no need to invoke higher-level selection to explain cultural or genetic evolution. Certain societies may, however, be more successful than other societies as a byproduct of their culture, provided that certain cultural trends remain stable across generations and are more effective at promoting group survival than are other cultural trends. For example, whereas parents may violently discipline their children in one society, another society's cultural practice of patient instruction and compassion may have greater longevity.

Humans, like most mammals, possess adaptations for enhancing our reproductive opportunities (see Buss, 2003, for review). We likely employ psychological process to maintain sexual access to desired mates as well as to deceive and manipulate sexual rivals. Mate retention behaviors, for instance, may be used to prevent our sexual partners from abandoning us for other reproductive opportunities. As discussed earlier, such behaviors can be abusive as well as nurturing. To the extent that mate retention behaviors are employed to benefit one's reproductive prospects, a certain amount of manipulation is inherent in such behaviors, even if they display generosity or compassion. Likewise, individuals can psychologically manipulate their sexual rivals via deception, as well as via intimidation and aggression. In both instances, strategies are employed to manipulate a sexual rival's behavior for one's own reproductive benefit. With the aid of language, humans may employ gossip and competitor derogation tactics to psychologically manipulate prospective mates away from sexual competitorsessentially manipulating the mate choices of their sexual targets in an extended phenotypic fashion, leading to the selection of genes that enable such manipulation (provided that the manipulation is evolutionarily successful). These tactics also vary by sex (see Buss, 2003, for review). Because men more than women value physical attractiveness in a romantic partner, women are more likely than men to derogate their sexual competitors' appearance ("Look at her fat thighs!"). On the other hand, because women more than men value current or potential resource holdings in a romantic partner, men are more likely than women to derogate their sexual competitors' earning potential and lack of social standing ("He's not going anywhere in life!").
When applied to the moral systems of cultures, manipulation of individuals for the sake of one's own reproductive interests is manifest on much larger scales. For example, men in polygynous societies whose wives reside in separate houses may lessen the threat of cuckoldry and sperm competition by requiring their wives or other men (their sexual competitors) to undergo genital mutilation (Wilson, 2008). Whatever proximate explanations such cultural practices may have (i.e., religious, aesthetic, initiatory, etc.), they may ultimately serve the evolutionary function of reducing paternity uncertainty and preventing investment in genetically unrelated offspring. If correct, Wilson's analysis may have uncovered evidence for culture-wide manipulative practices that are still prevalent in many societies, including our own. Depending on the society, failure to comply with such rituals may lead to social ostracism or even death. A similar phenomenon may help to explain culturally sanctioned monogamy and its social repercussions. The moral values associated with monogamy may reflect manipulative strategies by which genetically inferior men maximize their reproductive prospects by limiting the sexual opportunities of genetically superior men (see Pinker, 1997). Female dress codes within certain Muslim societies may likewise be strategies by which men manipulate the sexual opportunities of their wives and other female family members. Likewise, women whose reproductive prospects are at stake may be complicit and even supportive of such practices if they can thereby reduce their competitors' genetic success. As is reflected in the results of research investigating parent-offspring conflict over mating decisions (e.g., Apostolou, 2010), families in such societies may exert control over their daughters' or sisters' sexual choices via the institution of arranged marriage and the threat of an "honor" killing if they fail to comply. The fact that such practices are so prevalent in Arab cultures may reflect the long history of agropastoralism within these societies (Apostolou, 2010). The accumulation of wealth that comes with agropastoralism may put pressure on male resource holders to maintain their wealth and to prevent the squandering of their resources on relatives who reduce their genetic prospects with their mate choices.

Our psychological processes are amenable to a variety of cultural contexts and can creatively synthesize cultural information in novel ways, which may explain why cultural information changes so rapidly. Although our genetic processes and familial conflicts are more or less predictable, their cultural expression varies across time and space. For example, the universal experience of parentoffspring conflict emerges through widely different cultural manifestations. The counterculture movement of the 1960s, for instance, may have tapped into the psychological adaptations by which offspring counteract parental manipulation. Thus, the expression of "free love" may have been a culture-wide expression of evolved mechanisms used by offspring to rebel against the influence of parents on their mating decisions. It is doubtful whether "free love" was ever truly "free" as individuals choose mates based on their evolved mating preferences. However, rebellion against parental control of mating decisions may have had adaptive value for offspring in ancestral times (Apostolou, 2009). Likewise, the recent embracement of rap music and urban dress by white, suburban youths may reflect adaptive niche-seeking behaviors by which individuals attract mates of their own choosing. In such instances, parental reproductive interests may be threatened by their offspring's free exercise of mate choice. Parents, in turn, may 
represent their genetic interests through their own cultural expressions. Conservative ideals and "family values" may be extended phenotypic manifestations by which parents attempt to influence offspring behavior by influencing social norms and morals. Further research is needed to identify the specific design features of various cultural trends and to examine the extent to which they reflect the evolutionary products of familial conflict. For example, parallels may be drawn between various youth movements and the adaptive behaviors by which offspring manipulate caregivers. Likewise, personality and familial-context factors can be examined for correlations with individual membership in various groups, religions, and political movements.

Thus, many of our modern rules of conduct may reflect the overextension of normally functional adaptations for enforcing morals and values upon family members to densely populated environments for which they were not selected. Our ancestors did not evolve in environments containing millions of densely packed humans sharing a radius of a few square miles, as in Tokyo and Manhattan. Although selection may have sped up with the onset of agriculture (as population growth brought about greater genetic diversity on which selection could act-see Cochran \& Harpending, 2009), an interconnected world of close to seven billion humans is historically unprecedented. The legal and judicial systems of modern states may reflect the cooptation of naturally or sexually selected moral sentiments to a much wider circle of interacting individuals. Thus, order and stability is achieved via the redirection of ancestral moral sentiments that were originally limited to familial and reciprocal interactions. Although governments (often aided by state religion) can bring about smooth and efficient systems of cooperation and nonviolent competition, they may also enforce rules and ordinances by which the reproductive interests of some individuals are curbed for the benefit of others-usually those enforcing the particular rules and ordinances. This may be a result of the overextension of manipulative adaptations by which humans attempt to influence the behavior of family members and unwary reciprocators. This is to be expected if family members and other interactants possess traits for manipulating the behavior of their reproductive rivals, effectively utilizing their fellow humans as extended phenotypes of their own selfish genes. Our lives may be saturated with interconnected webs of manipulation by which some individuals or groups influence the behavior of other individuals or groups. Nowadays, these webs have grown to unprecedented complexity and reach with the aid of modern communication and transportation technologies.

Even though all humans possess adaptations for benefitting kin and cooperating with reciprocators, the cross cultural variation in morals, values, and taboos may reflect the variety of forms by which humans attempt to manipulate other humans in their environments. As noted by Qirko (2004), religious and political systems may hijack our adaptations for benefitting kin into allocating investment to nonrelatives by loading sermons, rituals, and political speeches with kin-based terms such as "brothers and sisters." Likewise, our evolved tendencies to benefit those who may benefit us in the future may be taken advantage of by social systems that may never reciprocate (i.e., by promising heavenly rewards or utopian dreams). This is not to deny the potential reproductive benefits that individuals may enjoy by sacrificing on behalf of political or religious groups (Atran, 2002), but as with any cooperative relationship, there is always a risk of defection. Group- level systems of morality and ethics may reflect cooperative as well as manipulative adaptations, whether cognitive or emotional, by which individuals enforce rules of conduct upon their family members and acquaintances. Likewise, our evolved systems may be manipulatively subverted into pathways that are detrimental to our survival and reproductive prospects as easily as they can be coopted for more benign purposes. For instance, evolved attachment systems that are usually directed toward caregivers may be activated by emotional pleas to "accept the love and guidance" of a "heavenly father" or a "holy mother" (see Kirkpatrick, 2004, for the application of attachment systems to supernatural agents). Similarly, manipulative adaptations used to maximize one's inclusive fitness may transform into nepotistic moral systems that support royal families and other dynasties. If parents and offspring can adaptively manipulate each other's behavior through discipline, moral instructions, and emotional expressions (as is expected from the theory of parent-offspring conflict), then ethical systems may reflect manipulative as well as cooperative forms of behavioral control that are extended to the wider society. Finally, evolved defenses against manipulation may be culturally expressed as consumer protection services, government regulations, and media-generated information campaigns, although the biological correlates of these social mechanisms may be tenuous or difficult to test. However, scholars should not shirk the opportunity to uncover the extent to which societal laws, norms, and morals reflect cooperative, manipulative, and defensive extensions of human biological traits. Such an investigation can be especially fruitful if it is grounded within a proper evolutionary perspective.

\section{Conclusion: Toward an Evolutionarily Enlightened Humanity}

Our discussion of the evolutionary processes that underlie many of our interactions with family, friends, coworkers, strangers, and social structures and institutions, should not be interpreted as value judgments on these relationships. Even if there are manipulative adaptations which humans and nonhumans employ in their dealings with other organisms, we may ultimately accept the manipulative nature of such relationships and continue to engage in them. For example, if our pets are ultimately coevolved parasites that take advantage of our propensity to care for anything with infantlike features, should we then abandon our dogs and cats (see Archer, 1997, but also see Serpell, 1991, and Wells, 2009, for possible health and reproductive benefits of pet-keeping)? Likewise, should we not adopt genetically unrelated offspring if adoption results from the misfiring of otherwise functional parental adaptations (e.g., Volk \& Quinsey, 2006)? Such questions are absurd precisely because our evolved nature enables us to circumvent our genetic interests. Natural selection has provided us with adaptations that were successful at propagating our ancestors' genes, but only on average, and only within ancestral environments. It does not guarantee that we will always pursue the best way to spread our genes in the here and now, or even spread our genes at all. A related phenomenon, often referred to as the naturalistic fallacy, is the mistaken assumption that explaining our biological nature is tantamount to an endorsement of it. If manipulating family members and friends for our own reproductive benefit is a result of evolved mechanisms, should we then tacitly accept such manipulation as an unavoidable outcome of our evo- 
lutionary past? Only by understanding the evolutionary dynamics behind life's veneer can we hope to transcend our most sordid tendencies.

Overcoming our noxious predispositions may be a Sisyphean task. Our evolved capacities to deceive and manipulate one another may be unprecedented in their destructive potential. Nuclear, chemical, and biological weapons, nationalistic bigotries, religious fundamentalist threats, environmental degradation, and the power that communicative technologies provide for despots and demagogues intent on seducing the minds of millions, all speak to the dangers that some of our evolved mechanisms pose to our wellbeing. What gives us a sense of optimism, however, is the rapid advancement of human knowledge. By understanding evolutionary arms races and the nature of viruses and bacteria, we have been able to devise vaccines and cures for some of the deadliest diseases that have plagued humanity. With advancements in genetic engineering, we are able to feed millions of individuals with nutritious, calorie-rich foods. With market economies, we can bring about reciprocal relationships that transcend cultural, ethnic, racial, and national boundaries. With the aid of global communications systems, we can expand our circle of kinship and in-group favoritism to include nonrelatives and even nonhuman endangered species. With an increasing awareness of our environmental impact, we can begin to take steps to alleviate our destructive footprints upon this planet. The future, however, is far from certain.

As evolutionary scientists, our aim is to uncover the ultimate explanations for the proximate workings of our biological world. We hope this article takes a step toward accomplishing this task by stripping away some of the self-deceptive layers with which humanity has been clothed for millions of years. We spend most of our lives interacting with kin. By understanding the evolutionary dynamics of the family, we believe that individuals can make better informed decisions regarding themselves, their kin, and their societies. Aside from such practical implications, we hope that biological treatments of human behavior and culture can instruct and enlighten those interested in humanity's inner workings. There is, however, much that remains undiscovered. It rests upon researchers from diverse fields to correct many of our errors, oversights, and misconceptions. Empirical research is essential in corroborating or refuting the speculative nature of some of our inquiries. As with all science, the study of human evolution is a work in progress.

\section{References}

Apostolou, M. (2009). Parent-offspring conflict over mating: The case of short-term mating strategies. Personality and Individual Differences, 47, 895-899.

Apostolou, M. (2010). Sexual selection under parental choice in agropastoral societies. Evolution and Human Behavior, 31, 39-47.

Archer, J. (1997). Why do people love their pets? Evolution and Human Behavior, 18, 237-259.

Atran, S. (2002). In gods we trust: The evolutionary landscape of religion. Oxford: Oxford University Press.

Belsky, J. (2000). Conditional and alternative reproductive strategies: Individual differences in susceptibility to rearing experience. In J. Rodgers, D. Rowe, \& W. Miller (Eds.), Genetic influences on human fertility and sexuality: Theoretical and empirical contributions from the biological and behavioral sciences (pp. 127-146). Boston: Kluwer.
Bjorklund, D. F., \& Pellegrini, A. D. (2002). The origins of human nature: Evolutionary developmental psychology. Washington, DC: American Psychological Association.

Bjorklund, D. F., Periss, V., \& Causey, K. (2009). The benefits of youth. European Journal of Developmental Psychology, 6, 120-137.

Brown, R. M., Brown, S. L., Johnson, A., Olsen, B., Melver, K., \& Sullivan, M. (2009). Empirical support for an evolutionary model of self-destructive motivation. Suicide and Life-Threatening Behavior, 39, $1-12$.

Buss, D. M. (1987). Love acts: The evolutionary biology of love. In R. J. Sternberg \& M. F. Barnes (Eds.), The psychology of love (pp. 100-118). New Haven: Yale University Press.

Buss, D. M. (2003). The evolution of desire: Strategies of human mating (rev. ed.). New York: Basic Books.

Chrastil, E. R., Getz, W. M., Euler, H. A., \& Starks, P. T. (2006). Paternity uncertainty overrides sex chromosome selection for preferential grandparenting. Evolution and Human Behavior, 27, 206-223.

Coall, D. A., \& Chisholm, J. S. (2010). Reproductive development and parental investment during pregnancy: Moderating influence of mother's early environment. American Journal of Human Biology, 22, 143-153.

Cochran, G., \& Harpending, H. (2009). The 10,000 year explosion: How civilization accelerated human evolution. New York: Basic Books.

Cosmides, L., \& Tooby, J. (2005). Neurocognitive adaptations designed for social exchange. In D. M. Buss (Ed.), The handbook of evolutionary psychology (pp. 584-627). Hoboken: Wiley.

Cronk, L. (1995). Is there a role for culture in human behavioral ecology? Ethology and Sociobiology, 16, 181-205.

Daly, B., \& Morton, L. L. (2009). Empathetic differences in adults as a function of childhood and adult pet ownership and pet type. Anthrozoos, 22, 371-382.

Darwin, C. R. (1859/1964). On the origin of species. Cambridge, MA: Harvard University Press.

Dawkins, R. (1976). The selfish gene. Oxford: Oxford University Press.

Dawkins, R. (1982). The extended phenotype. Oxford: Freeman.

Earley, R. L. (2010). Social eavesdropping and the evolution of conditional cooperation and cheating strategies. Philosophical Transactions of the Royal Society B, 365, 2675-2686.

Goetz, A. T., Shackelford, T. K., Romero, G. A., Kaighobadi, F., \& Miner, E. J. (2008). Punishment, proprietariness, and paternity: Men's violence against women from an evolutionary perspective. Aggression and Violent Behavior, 13, 481-489.

Hagen, E. H. (2002). Depression as bargaining: The case postpartum. Evolution and Human Behavior, 23, 323-336.

Haig, D. (2004). Genomic imprinting and kinship: How good is the evidence? Annual Review of Genetics, 38, 553-585.

Haig, D. (2010). Colloquim Papers: Transfers and transitions: Parentoffspring conflict, genomic imprinting, and the evolution of human life history. Proceedings of the National Academy of Science, USA, 107(Suppl, 1), 1731-1735.

Hamilton, W. D. (1964). The genetical evolution of social behaviour (I and II). Journal of Theoretical Biology, 7, 1-52.

Harris, J. R. (2009). The nurture assumption: Why children turn out the way they do (rev. ed.). New York: Free Press.

Hudson, R., \& Trillmich, F. (2008). Sibling competition and cooperation in mammals: Challenges, developments, and prospects. Behavioral Ecology and Sociobiology, 62, 299-307.

Kaighobadi, F., Shackelford, T. K., Popp, D., Moyer, R. M., Bates, V. M., \& Liddle, J. R. (2009). Perceived risk of female infidelity moderates the relationship between men's personality and partner-directed violence. Journal of Research in Personality, 43, 1033-1039.

Kirkpatrick, L. A. (2004). Attachment, evolution, and the psychology of religion. New York: Guilford Press. 
Kurland, J. A., \& Gaulin, S. J. C. (2005). Cooperation and conflict among kin. In D. M. Buss (Ed.), The Handbook of Evolutionary Psychology (pp. 447-482). Hoboken, NJ: Wiley.

Lee, C., \& Slade, P. (1996). Miscarriage as a traumatic event: A review of the literature and new implications for intervention. Journal of Psychosomatic Research, 40, 235-244.

Lummaa, V., Vuorisalo, T., Barr, R. G., \& Lehtonen, L. (1997). Why cry? Adaptive significance of intensive crying in human infants. Evolution and Human Behavior, 19, 193-202.

Maestripieri, D., Hoffman, C. L., Anderson, G. M., Carter, C. S., \& Higley, J. D. (2009). Mother-infant interactions in free-ranging rhesus macaques: Relationships between physiological and behavioral variables. Physiology \& Behavior, 96, 613-619.

Melis, A. P., \& Semmann, D. (2010). How is human cooperation different? Philosophical Transactions of the Royal Society B, 365, 2663-2674.

Miller, G. (2000). The mating mind: How sexual choice shaped the evolution of human nature. London: Heineman.

Miner, E. J., \& Shackelford, T. K. (2010). Mate attraction, retention, and expulsion. Psichothema, 22, 9-14.

Neberich, W., Penke, L., Lehnart, J., \& Asendorpf, J. B. (2010). Family of origin, age at menarche, and reproductive strategies: A test of four evolutionary-developmental models. European Journal of Developmental Psychology, 7, 153-177.

Patten, M. M., \& Haig, D. (2008). Reciprocally imprinted genes and the response to selection on one sex. Genetics, 179, 1389-1394.

Pinker, S. (1997). How the mind works. New York: Norton.

Pinker, S. (2002). The blank slate: The modern denial of human nature. New York: Viking.

Qirko, H. N. (2004). Altruistic celibacy, kin-cue manipulation, and the development of religious institutions. Zygon, 39, 681-706.

Rousseau, J. J. (1755/1994). Discourse upon the origin and foundation of inequality among mankind. New York: Oxford University Press.

Salmon, C. A. (1998). The evocative impact of kin terminology in political rhetoric. Politics and the Life Sciences, 17, 51-57.

Salmon, C. A. (1999). On the impact of sex and birth order on contact with kin. Human Nature, 10, 183-197.

Salmon, C. A. (2005). Parental investment and parent-offspring conflict. In D. M. Buss (Ed.), The handbook of evolutionary psychology (pp. 506527). Hoboken, NJ: Wiley.
Serpell, J. A. (1991). Beneficial effects of pet ownership on some aspects of health and behavior. Journal of the Royal Society of Medicine, 84, $717-720$.

Symons, D. (1979). The evolution of human sexuality. New York: Oxford University Press.

Tooby, J., \& Cosmides, L. (1992). The psychological foundations of culture. In J. Barkow, L. Cosmides, \& J. Tooby (Eds.), The adapted mind (pp. 19-136). New York: Oxford University Press.

Trivers, R. (1974). Parent-offspring conflict. American Zoologist, 14, 249 264.

Trivers, R. (1985). Social evolution. Menlo Park, CA: BenjaminCummings.

Trivers, R. L. (1972). Parental investment and sexual selection. In B Campbell (Ed.), Sexual selection and the descent of man, 1871-1971 (pp. 136-179). Chicago: Aldine-Atherton.

Trivers, R. L. (1971). The evolution of reciprocal altruism. Quarterly Review of Biology, 46, 35-57.

Volk, A. A., \& Quinsey, V. L. (2006). The influence of cues of high and low body weight on adults' ratings in the Hypothetical Adoption Paradigm. The Scientific World Journal, 6, 1574-1582.

Watts, D. P. (1994). Social relationships of immigrant and resident female mountain gorillas II: Relatedness, residence, and relationships. American Journal of Primatology, 32, 13-30.

Watts, D. P., \& Mitani, J. C. (2001). Boundary patrols and intergroup encounters in wild chimpanzees. Behaviour, 138, 299-327.

Wells, D. L. (2009). The effects of animals on human health and wellbeing. Journal of Social Issues, 65, 523-543.

Williams, G. C. (1966). Adaptation and natural selection: A critique of some current evolutionary thought. Princeton, NJ: Princeton University Press.

Wilson, C. G. (2008). Male genital mutilation: An adaptation to sexual conflict. Evolution and Human Behavior, 29, 149-164.

Received May 25, 2010

Revision received September 3, 2010 Accepted September 6, 2010 